\title{
Effect of tween 80 added to the soil on the degradation of endosulfan by Pseudomonas aeruginosa
}

\author{
${ }^{*}$ R. Jayashree, N. Vasudevan
}

Centre for Environmental Studies, Anna University, Chennai - 600 025, India

Received 4 August 2006; revised 25 February 2007; accepted 6 March 2007; available online 20 March 2007

\begin{abstract}
Endosulfan, a chlorinated cyclodiene insecticide is of environmental concern because of its apparent persistence and toxicity to many non target organisms. Endosulfan is hydrophobic and persists in soil for more than a year. To overcome the problem of hydrophobic and limited availability, surfactants play a major role in soil remediation. In the present study, the effect of Tween 80 added to the soil on the degradation of endosulfan by Pseudomonas aeruginosa at different $\mathrm{pH}$ (7.0 and 8.5) was studied. The addition of synthetic surfactant Tween 80 enhanced the solubility and degradation of endosulfan. A significant degradation (94\%) was observed in $\mathrm{pH} 8.5$ and Tween 80 added soil; the bacterial population in the treatment unit T8 was $75 \times 10^{9} \mathrm{CFU} / \mathrm{g}$ of soil. The unit T4 inoculated at pH 8.5 showed $86 \%$ alpha and $60 \%$ beta endosulfan degradation, the bacterial population was $73 \times 10^{8} \mathrm{CFU} / \mathrm{g}$ of soil. The degradation of both the isomers were observed and accompanied with formation of endodiol and endosulfan sulfate.
\end{abstract}

Key words: Tween 80, pH, endosulfan, degradation, Pseudomonas aeruginosa

\section{INTRODUCTION}

Endosulfan is a chlorinated cyclodiene insecticide currently used throughout the world for the control of numerous insects in a wide variety of food and nonfood crops. Endosulfan has been ubiquitously detected in the atmosphere, soils, sediments, surface waters, rainwaters and foodstuffs (Kwon, et al., 2002). Endosulfan comprises two parent isomers alpha and beta endosulfan and the alpha to beta ratio of technical endosulfan is about 7:3 and both isomers are extremely toxic to aqueous organisms. Many bacteria and fungi including Cornybacterium sp., Nocardia sp., Mycobacterium sp., Pseudomonas fluorescens, Penicillium sp., Aspergillus sp., Phanerochaete chrysosporium have been reported to be endosulfan degraders. (Kullmann and Matsumura, 1996). Endosulfan could be degraded by attack on the sulfite group by oxidation and or hydrolysis to form the toxic endosulfan sulfate and the nontoxic endosulfan diol respectively. (Baar and Aust, 1987). The problem of endosulfan bioremediation is poor solubility and restriction of appropriate biocatalyst. The synthetic surfactant Tween 80 was non-toxic to soil microorganisms and inert to the soil matrix and had the additional benefit of causing an enhanced dissolution rate for single compounds. (Angela link, 2000). Despite

\footnotetext{
*Corresponding author, Email: p_tamil@yahoo.com

Tel./Fax: +91-9884787202
}

the many advantages of surfactin over chemical surfactants for bioremediation, its use has been limited on account of the high production cost. Bury and Miller (1993) found that uptake of micellar n-decane and ntetradecane was stimulated by a biodegradable synthetic surfactant resulting in higher growth rates. This was probably caused by direct uptake of the hydrocarbons along with the micelles. Aronstein and Alexander (1993) reported that synthetic surfactant at low concentrations may be useful for bioremediation of sites contaminated with hydrophobic pollutants. Singer and Finnerty (1984) reported that the addition of Tween 80 stimulated utilization of hexadecane by several strains of Pseudomonas aeruginosa. Wong, et al., 2004 reported that Pseudomonas aeruginosa when combined with Tween 80 effectively enhanced the solubility and degradation of phenanthrene and they also reported that Tween 80 is biodegradable. Volkering, et al., (1995) reported that the oxygen uptake rate of bacterial cells was not affected in the presence of surfactants. They also reported that surfactant concentrations up to $10 \mathrm{~g} / \mathrm{L}$ can be used without any toxicity effect on microorganisms. Soil $\mathrm{pH}$ also play a vital role in the degradation process. Some of the bacteria favour a $\mathrm{pH}$ near neutral and some are highly tolerant to alkaline conditions. The environmental fate of endosulfan in soils is influenced 
by the $\mathrm{pH}$, texture, moisture content and also by the presence of organic matter and co-pollutants. The rate of degradation is a function of the prevailing temperature, moisture regime, the content, type of organic matter and clays present (Kookana, et al., 1998).

In the present study we have isolated an endosulfan degrader, Pseudomonas aeruginosa through intensive screening from endosulfan polluted soil samples. In addition, Tween 80 was added to the bacterial culture at different $\mathrm{pH}$ (7 and 8.5) conditions to enhance the bioavailability and complete elimination of endosulfan from the contaminated soil.

\section{MATERIALS AND METHODS}

Chemicals

Endosulfan standards (a-endosulfan, b-endosulfan and its metabolites) were purchased from M/s. Chem Service Inc., West Chester, USA with a purity of $98 \%$. A standard and stock solutions were prepared with nhexane. The stock solution (1000 mg/mL) of each compound and stored in a refrigerator at $4{ }^{\circ} \mathrm{C}$. All stock solutions were prepared and stored at $-20^{\circ} \mathrm{C}$. Commercial endosulfan was purchased from Jayaprakash Fertilizers Agency, Thiruvallur district. The non-ionic surfactant Tween 80 and 2-phenoxy ethanol were obtained from Sigma Chemical Co., USA. All other chemicals, solvents and reagents used in the study were of analytical grade.

\section{Enrichment and isolation of bacterial strain}

Two grams of soil samples was taken in a $250 \mathrm{~mL}$ Erlenmeyer flask containing $50 \mathrm{~mL}$ of liquid mineral medium (Ammonium chloride $1.0 \mathrm{~g}$, Potassium dihydrogen orthophosphate $2.0 \mathrm{~g}$, Dipotassium hydrogen orthophosphate $7.5 \mathrm{~g}$, Magnesium sulphate $0.2 \mathrm{~g}$, Sodium chloride $0.5 \mathrm{~g}$, Calcium carbonate $0.2 \mathrm{~g}$, Glucose 1.0 g, Distilled water $1.0 \mathrm{~L}$, pH 7.8 and agar $15 \%$ was added to solid medium) with $50 \mu \mathrm{g} / \mathrm{mL}$ of endosulfan and was incubated for 7 days in a rotary shaker (IKA, Germany) at $130 \mathrm{rpm}$. Five millilitres of culture broth from individual flask culture was re-inoculated to $50 \mathrm{~mL}$ of endosulfan mineral salt medium and further cultured at $30^{\circ} \mathrm{C}$ for 7 days. Enrichment of the culture was done by repeated transfers. Then $0.1 \mathrm{~mL}$ of culture broth was plated on solid endosulfan mineral salt medium for isolating single colonies. The single colonies were characterized and identified as a Pseudomonas aeruginosa using biochemical tests (Table 1 ). The culture was maintained on mineral agar slants.

\section{Growth studies}

A loopfull of P.aeruginosa grown on mineral agar slant was inoculated into $250 \mathrm{~mL}$ conical flasks containinig $50 \mathrm{~mL}$ medium amended with endosulfan as substrate. The flasks were kept for $24 \mathrm{~h}$ on an orbital rotary shaker set at $130 \mathrm{rpm}$ at $30^{\circ} \mathrm{C}$ for the growth of the organism. Growth was measured at $24 \mathrm{~h}$ as viable cell count as well as turbidity at $550 \mathrm{~nm}$. The cells were harvested by centrifugation at $5000 \mathrm{~g}$ for $10 \mathrm{~min}$. The cell pellet was washed twice in $15 \mathrm{mM}$ phosphate buffer, $\mathrm{pH} 7$. The washed cells were used for degradation study ( $\left.2 \times 10^{5} \mathrm{CFU}\right)$.

\section{Soil}

The soil selected for this study was collected from Thiruvallur district had no previous exposure to pesticides and was classified as sandy loam. The soil was air dried and sieved through $2 \mathrm{~mm}$ sieve. The carbon content of the soil was estimated using TOC analyzer (Analytic gena, micro C). The $\mathrm{pH}$ of the sample was estimated as per the methods of Trivedy and Goel (1986) $\mathrm{pH}$ of the soil was 8.1 , organic carbon $0.12 \%$. The portions of soil were adjusted to $\mathrm{pH}$ values of 7.0 and 8.5 by the addition of $2 \mathrm{NHCl}$ or $1 \mathrm{~N} \mathrm{NaOH}$. Adjustments to desired $\mathrm{pH}$ were made three times over 10 days till the $\mathrm{pH}$ of the soil were stabilized. Excess liquid from each soil was drained after $\mathrm{pH}$ adjustment and commercial endosulfan 35EC was added to give a concentration of $2.35 \mathrm{mg} / \mathrm{g}$ active ingredient (compound that kills or controls the target pest). After air drying for 24 - $48 \mathrm{~h}$, the soil was pulverized and used for degradation studies.

\section{Degradation of endosulfan in $\mathrm{pH}$ adjusted soils}

For each $\mathrm{pH}$ adjusted soil, 4 sets were made containing $20 \mathrm{~g}$ soil in each set's and Tween 80 was added at CMC (A phenomenon unique to surfactants is the self-assembly of molecules into dynamic clusters called micelles. Micelle formation occurs above a critical concentration of surfactant monomers referred to as the Critical Micelle Concentration (Miller and Zhang, 1997). Three replicates were maintained for each set. Experimental details were presented in Table 2. All the sets were received $6 \mathrm{~mL}$ of mineral medium without glucose. Distilled water was added to compensate the evaporational loss of water and soil was kept at $30^{\circ} \mathrm{C}$ for 8 weeks and $1.2 \mathrm{~g}$ samples were taken at weekly intervals to quantify the residual endosulfan present in each soil sample. 


\section{Bacterial count}

During the degradation process, the bacterial population (plate count technique) was monitored at weekly intervals. One gram of soil was taken and incubated for $30 \mathrm{~min}$ with $100 \mathrm{~mL}$ of sterile water at 30 ${ }^{\circ} \mathrm{C}$ at $150 \mathrm{rpm}$. A $100 \mathrm{~mL}$ sample of appropriate dilution of the soil suspension was inoculated onto nutrient agar plates. The plates were incubated at $30^{\circ} \mathrm{C}$ for $24 \mathrm{~h}$ and the number of colonies were counted.

\section{Extraction of residual endosulfan from the soil}

Approximately $1.2 \mathrm{~g}$ of wet soil was removed from the different treatments and air dried. One gram of dried soil was transferred to a test tube and extracted with 3 $\mathrm{mL}$ of ethyl acetate by vortexing. The ethyl acetate layer was decanted after $5 \mathrm{~min}$. This extraction was repeated five times. The ethyl acetate fractions were pooled, passed through anhydrous sodium sulfate (5 g) and florosil (1 g) mixture and evaporated at room temperature. (Awasthi, et al., 2000).

\section{Chromatographic analysis}

Pesticide residue was dissolved in acetone and an aliquot containing 5-10 mg of endosulfan was spotted on a silica gel plate and the chromatogram was developed in hexane: chloroform: acetone (9:3:1). The separated spots were visualized by spraying the chromogenic reagent $\left(\mathrm{AgNO}_{3}\right.$ in 2-phenoxy ethanol) (Kovacs, 1965). For gas chromatography, the residual pesticide was dissolved in $1 \mathrm{~mL}$ of acetone, diluted to $10^{6}$ times with n-hexane, and analysed as per the above said procedure. One microlitre from each of

Table 1: Biochemical test for Pseudomonas aeruginosa

\begin{tabular}{ll}
\hline Biochemical test & Results \\
\hline Indole & Negative \\
Citrate utilisation & Utilised \\
T. S. Iron Agar & $\mathrm{k} / \mathrm{k}$ \\
Fermentative / Oxidative (Hugh Leifson) & Oxidative \\
& fermentation \\
Oxidase & Positive \\
\hline
\end{tabular}

Table 2: Experimental set up

\begin{tabular}{ll}
\hline T1 & Soil $(\mathrm{pH} 7)+$ Endosulfan \\
\hline T2 & Soil $(\mathrm{pH} \mathrm{7)} \mathrm{+} \mathrm{Endosulfan} \mathrm{+} \mathrm{Pseudomonas} \mathrm{aeruginosa}$ \\
T3 & Soil $(\mathrm{pH} 8.5)+$ Endosulfan \\
T4 & Soil $(\mathrm{pH} 8.5)+$ Endosulfan + Pseudomonas aeruginosa \\
T5 & Soil $(\mathrm{pH} \mathrm{7)} \mathrm{+} \mathrm{Endosulfan} \mathrm{+} \mathrm{Tween} 80(0.1 \mathrm{~g} / \mathrm{L})$ \\
T6 & Soil $(\mathrm{pH} \mathrm{7)} \mathrm{+} \mathrm{Endosulfan} \mathrm{+} \mathrm{Tween} 80(0.1 \mathrm{~g} / \mathrm{L})$ \\
& + Pseudomonas aeruginosa \\
T7 & Soil (pH 8.5) + Endosulfan + Tween $80(0.1 \mathrm{~g} / \mathrm{L})$ \\
T8 & Soil (pH 8.5) + Endosulfan + Tween $80(0.1 \mathrm{~g} / \mathrm{L})$ \\
& + Pseudomonas aeruginosa \\
\hline
\end{tabular}

the final residue solutions was injected into the GC (Chemito) model 1000 chromatography equipped with a packed glass column (4'x1/8", filled with 60-80 mesh coated over chromosorb with a mixture of $1.5 \%$ OV17 and $1.95 \%$ QF) with ECD (Electron Capture Detector) for residue analysis in an injector temperature of $220^{\circ} \mathrm{C}$, oven temperature $190^{\circ} \mathrm{C}$, detector temperature $280^{\circ} \mathrm{C}$ and nitrogen as carrier gas $(27 \mathrm{~mL} / \mathrm{min})$. The qualitative identification of the endosulfan present in the samples was performed by comparing the relative retention times (RRT) with respect to the standard, for each peak in the real sample chromotogram to those RRT in the standard mixture chromotogram. The quantitative determination was performed by using the relative peak areas (RPA) and the relative concentrations (RC).

\section{Statistical analysis}

The values from triplicate samples were analyzed using analysis of variance (ANOVA), and Fisher's LSD was used to compare means. $P$ values less than 0.05 were considered significant.

\section{RESULTS}

Microbial methods to remediate hydrophobic organochlorines contaminated soils are often limited by low substrate solubilities which can reduce bioavailability to the degrading microorganisms. (Atlas and Cerniglia, 1995) Use of Tween 80 as a means of increased bioavailability of hydrophobic endosulfan to microorganisms under different $\mathrm{pH}$ (7.0 and 8.5) was studied.

\section{Effect of $\mathrm{pH}$ on endosoulfan degradation}

Treatment unit T2 at pH 7 showed $47 \%$ of alpha and $31 \%$ beta degradation, the bacterial population was 45 x $10^{7} \mathrm{CFU} / \mathrm{g}$ of soil. The control unit T1 recorded $15 \%$ of alpha and $13 \%$ of beta degradation; the bacterial population was $73 \times 10^{5} \mathrm{CFU} / \mathrm{g}$ of soil (Fig. 1).

The unit T4 inoculated at $\mathrm{pH} 8.5$ showed $86 \%$ alpha and $60 \%$ beta endosulfan degradation, the bacterial population was $73 \times 10^{8} \mathrm{CFU} / \mathrm{g}$ of soil. The control unit T3 (pH 8.5) showed $20 \%$ of alpha endosulfan and $19 \%$ of beta endosulfan degradation where the bacterial population was $43 \times 10^{6} \mathrm{CFU} / \mathrm{g}$ of soil (Fig. 2). A significant degradation was observed at $\mathrm{pH}$ 8.5. The maximum degradation at $\mathrm{pH} 8.5$ is mainly due to increased growth $\left(73 \times 10^{8} \mathrm{CFU} / \mathrm{g}\right.$ of soil) and activity of the bacteria in alkaline conditions. 
This could be due to better bioavailability of endosulfan and optimal biotic activity of cells at this $\mathrm{pH}$. At $8^{\text {th. }}$ week of incubation showed faster disappearance of both the isomers with the formation of metabolites. TLC studies revealed the formation of two metabolites such as endosulfan diol and endosulfan sulfate at pH 7.0 and 8.5 (Fig. 3). Endosulfan was subjected to degradation by oxidation and hydrolysis conclusively, endosulfan sulfate formation was found to be favoured as oxidative production and a novel hydrolysis product was identified as endosulfan diol.

Effect of Tween 80 on endosulfan degradation

The unit $\mathrm{T} 6$ ( $\mathrm{pH} 7$ with Tween 80 ) recorded $62 \%$ of alpha and $58 \%$ of beta endosulfan degradation. The bacterial population in the soil was $36 \times 10^{8} \mathrm{CFU} / \mathrm{g}$ of soil. The control unit (T5) showed $12 \%$ of alpha endosulfan and $11 \%$ of beta endosulfan degradation, the bacterial population in the soil was $5 \times 10^{6} \mathrm{CFU} / \mathrm{g}$ of soil (Fig. 4). When compared to Tween 80 with $\mathrm{pH} 7$ and 8.5, pH 8.5 with Tween 80 recorded maximum significant degradation of endosulfan isomers ( $94 \%$ of alpha and $84 \%$ of beta), the bacterial population in the treatment unit T8 was $75 \times 10^{9} \mathrm{CFU} / \mathrm{g}$ of soil. The control unit (T7) showed $18 \%$ of alpha and $13 \%$ of beta endosulfan degradation. The cell growth was increased to $10 \times 10^{6} \mathrm{CFU} / \mathrm{g}$ of soil (Fig. 5). The unit T8 (Pseudomonas aeruginosa with Tween 80), showed optimum the degradation of endosulfan isomers. The release of endosulfan, which is a hydrophobic compound was dramatically enhanced by the aqueous concentration of Tween 80 . Tween 80 might have reduced the interfacial tension of the soil organic matter and water, allowing to utilize the endosulfan by the microorganisms.

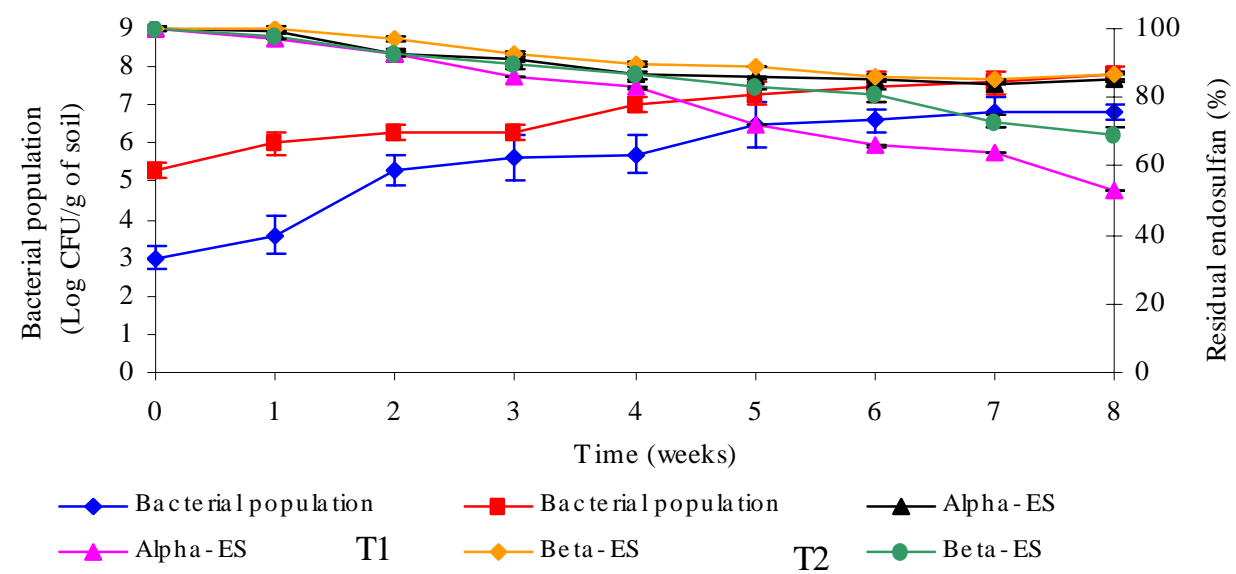

Fig. 1: Degradation of endosulfan (ES) at $\mathrm{pH} 7$

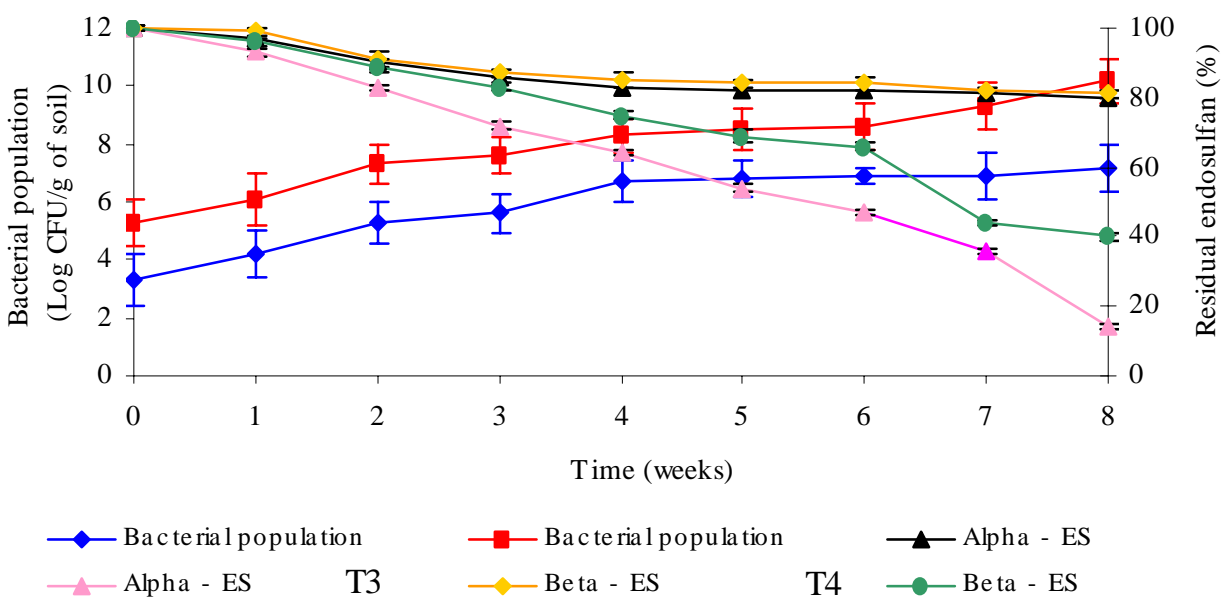

Fig. 2: Degradation of endosulfan (ES) at $\mathrm{pH} 8.5$ 
Int. J. Environ. Sci. Tech., 4 (2): 203-210, 2007
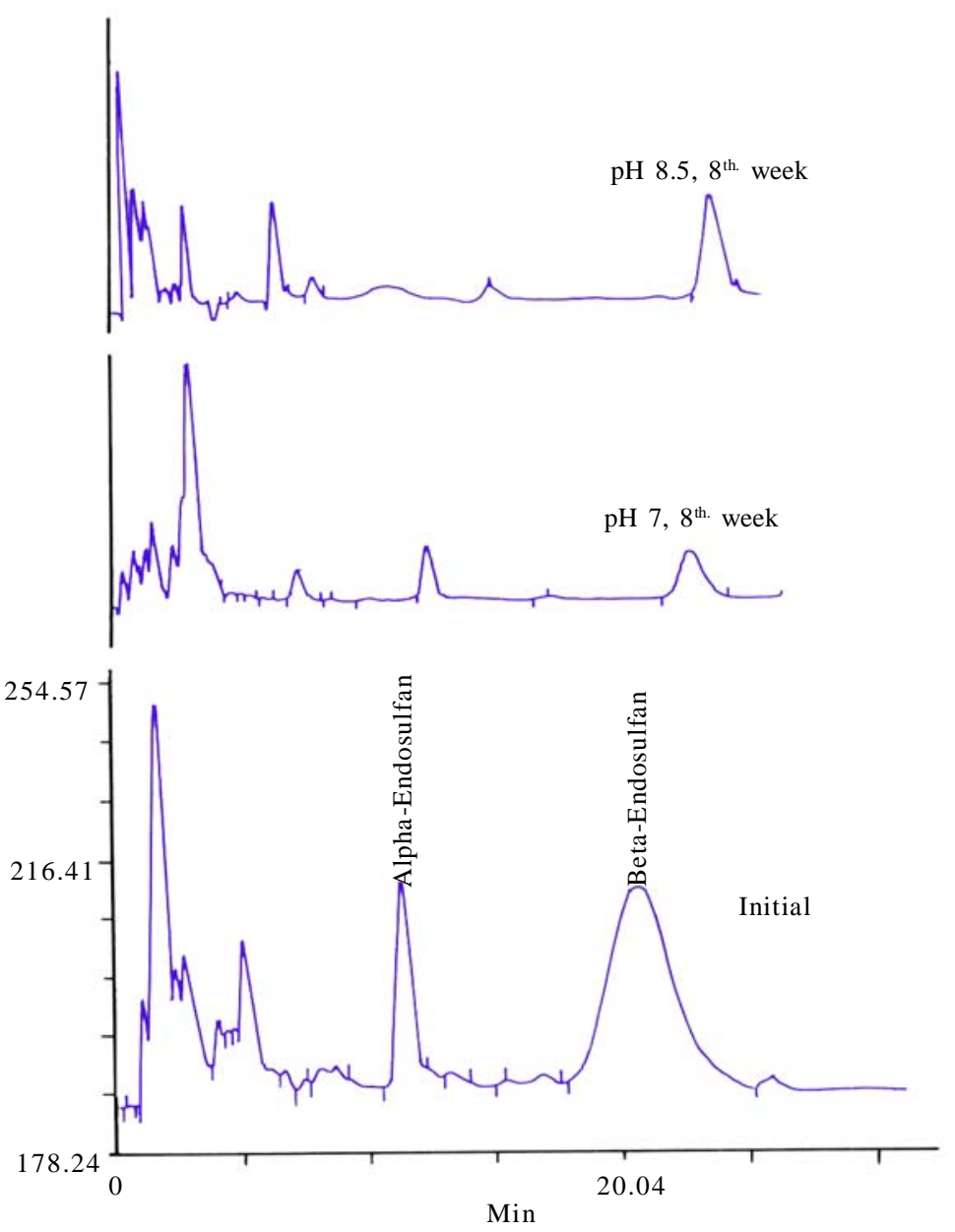

Fig. 3: Gas chromatographic profile of endosulfan degradation at $\mathrm{pH} 7.0$ and 8.5

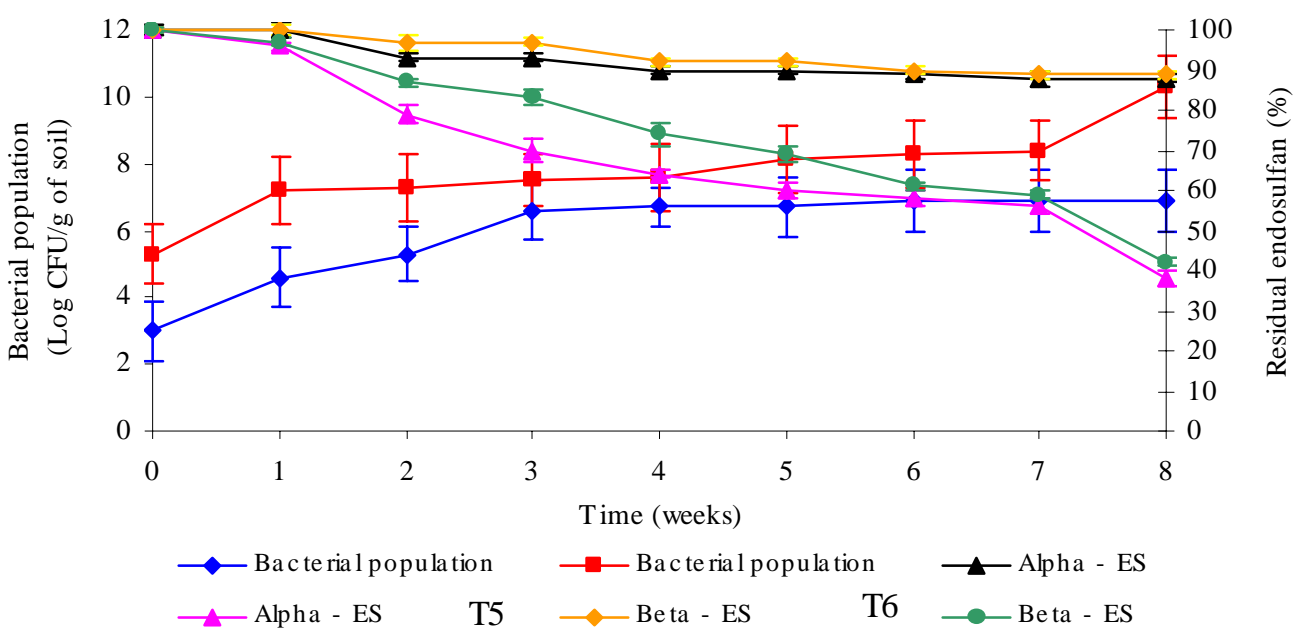

Fig. 4: Degradation of endosulfan (ES) with Tween 80 at $\mathrm{pH} 7$ 
R., Jayashree, N. Vasudevan

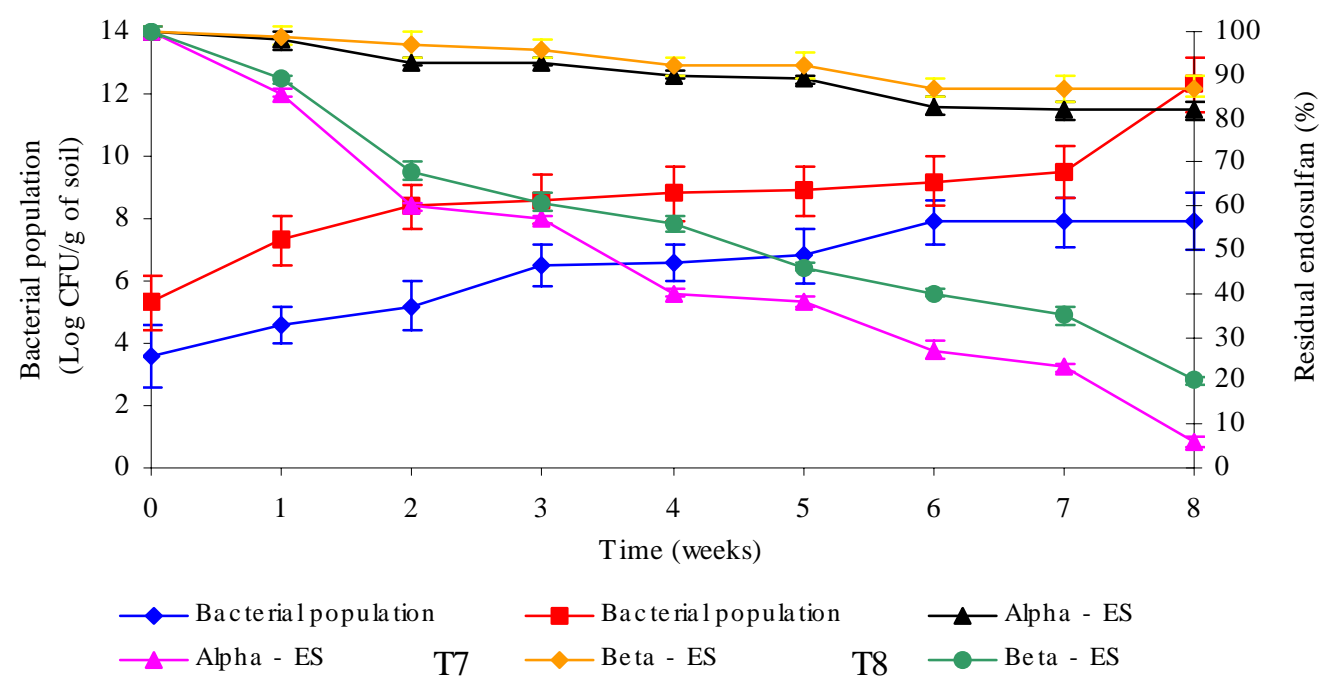

Fig. 5: Degradation of endosulfan (ES) with Tween 80 at $\mathrm{pH} 8.5$

\section{DISCUSSION AND CONCLUSION}

The maximum degradation at $\mathrm{pH} 8.5$ is mainly due to increased growth and activity of the bacteria in alkaline conditions. (Martens, 1976; Sutherland, et al., 2002; Awasthi, et al., 2002). This could be due to better bioavailability of endosulfan and optimal biotic activity of cells at this pH. Similarly Shalini Singh, et al., (2000) reported that the degradation rate of endosulfan is dependent on the $\mathrm{pH}$ of the soil. When compared to acidic, alkaline conditions favor the maximum degradation. The breakdown product, endosulfan sulfate is more persistent than the parent compound, accounting for $90 \%$ of the residue in 11 weeks. Kumar and Philip (2006) isolated the highly efficient endosulfan degrading bacterial strains from soil. A total of 29 bacterial strains were isolated through enrichment technique from 15 specific sites using endosulfan as sole sulfur source. The three bacterial strains, Pseudomonas spinosa, $P$. aeruginosa, and Burkholderia cepacia, were the most efficient degraders of both alpha- and beta-endosulfan as they consumed more than $90 \%$ of the spiked amount. Maximum biodegradation by these three selected efficient bacterial strains was observed at an initial $\mathrm{pH}$ of 8.0 and at an incubation temperature of $30^{\circ} \mathrm{C}$.

Kwon, et al., (2002) reported that the endosulfan diol is the major metabolite as $\mathrm{pH}$ increases, while endosulfan sulfate is the major metabolite as $\mathrm{pH}$ decreases. Kumar, et al., (2007) studied the degradation of endosulfan by a mixed culture isolated from a pesticide-contaminated soil was studied in batch experiments. After two weeks of incubation, the mixed culture was able to degrade $73 \%$ and $81 \%$ of alpha and beta endosulfan respectively. Two cultures identified by $16 \mathrm{~S}$ rRNA as Stenotrophomonas maltophilia and Rhodococcus erythropolis were found to be responsible for majority of the degradation by the mixed culture. S. maltophilia showed better degradation efficiency compared to that by $R$. erythropolis.

Lee, et al., (2006) isolated a bacterium through repetitive enrichment and successive subculture using endosulfan or endosulfan sulfate as the sole carbon source, The KS-2P was identified as Pseudomonas sp. on the basis of the results of a $16 \mathrm{~S}$ rDNA sequencing analysis and MIDI test. The degradation ratios for endosulfan or endosulfan sulfate in minimal medium containing endosulfan $(23.5 \mathrm{mug} / \mathrm{mL})$ or endosulfan sulfate (21 mug/mL) were $52 \%$ and $71 \%$, respectively. The results suggest that Pseudomonas sp. KS-2P has potential as a biocatalyst for endosulfan bioremediation.

Hussain, et al., (2007) reported that the alpha endosulfan degraded more readily than beta endosulfan and endosulfan sulfate. The half life of alphaendosulfan, beta-endosulfan and endosulphan sulfate was found to be 136.8, 273 and 301 days in sterilized Alfisol and 55, 256 and 277 days in non-sterilized Alfisol respectively. Shivaramaiah and Kennedy (2006) isolated three novel bacterial species, namely, Staphylococcus sp., Bacillus circulans-I, and Bacillus circulans-II, from contaminated soil collected from the premises of 
a pesticide manufacturing industry. Pure culture studies were revealed that the Staphylococcus sp. utilized more beta endosulfan compared to alpha endosulfan, whereas Bacillus circulans-I and Bacillus circulans-II utilized more alpha endosulfan compared to beta endosulfan.

The addition of Tween $80(0.1 \mathrm{~g} / \mathrm{L})$ in the treatment unit T8 might have emulsified the endosulfan, thereby increasing the amount of insecticide in contact with the soil bacteria. Surfactant even at very low concentration was shown to enhance the biodegradation of certain xenobiotics in soil (Haigh and Alcock, 1996). Aronstein and Alexander (1993) showed that nonionic surfactant (Novel 1111412-56) at $10 \mu \mathrm{g} / \mathrm{mL}$ added to the surface of lime silt loam soil enhanced the biodegradation of phenanthrene and biphenyl. The degradation of endosulfan predominantly describes the formation of endodiol and endosulfan sulfate. During the degradation process, hydrolysis takes place and endosulfan converted into endodiol. The endodiol is the major metabolite as $\mathrm{pH}$ increases. The formation of endodiol is the initial step in the degradation of endosulfan, further it may be converted into some other form. Endosulfan sulfate was the major metabolite at lower $\mathrm{pH}(\mathrm{pH} \mathrm{7)}$. The metabolites Endosulfan sulfate formed indicated that the organism follows an oxidative pathway for metabolism of this pesticide (Kumar and Philip, 2006). Endosulfan sulfate appeared to be a terminal pathway product. Most of the research has concentrated on the degradation of endosulfan in liquid medium. (Sethunathan, et al., 2002) A few studies carried out on the degradation of endosulfan in soil have been without surfactant amendment. (Trivedy and Goel,1986). This study proves that Pseudomonas aeruginosa combined with Tween 80 is able to achieve 94\% degradation of endosulfan in contaminated soil. Hence, surfactant enhanced degradation studies is a promising approach for remediating endosulfan contaminated soils.

\section{ACKNOWLEDGEMENT}

The authors would like to thank CSIR, New Delhi for the financial support throughout the period of this study.

\section{REFERENCES}

Angela link. (2000). Effect of non ionic surfactants on dissolution of polycyclic aromatic hydrocarbons from coal tar. Practice periodical of hazardous, Toxic Radio. Wast. Manag., 4, 78-81. Aronstein, B.N., Alexander, M., (1993). Effect of non ionic surfactant added to the soil surface on the biodegradation of aromatic hydrocarbons within the soil. Appl. Microbiol. Biotechnol., 39, 386-390.

Atlas, R.M., Cerniglia, C.E., (1995). Bioremediation of petroleum pollutants. Bioscience, 45, 332-338.

Awasthi, N., Ahuja, R., Kumar, A., (2000). Factors influencing the degradation of soil applied endosulfan isomers. Soil Biol. Biochem., 32, 1697-1705.

Awasthi, N., Singh, A.K., Jain, R.K., Khangorat, B.S., Kumar, A., (2002). Degradation and detoxification of endosulfan isomers by a defined co-culture of two Bacillus strains. Appl. Microbiol. Biotechnol., 62, 279-283.

Ajay S., Jonathan, D., Van Hamme, Ward, O.P., (2006). Surfactants in Microbiology and biotechnology, part-2. Application aspects. Biotechnol. Adv., 21(1), 7-23.

Baar, D.P., Aust, S.A., (1987). Mineralization of recalcitrant environmental pollutants by white rot fungus. In: proceedings of the National conference on Hazardous materials. 146-151.

Bury, S.J., Miller, C.A., (1993). Effect of micellar solubilization on biodegradation rates of hydrocarbons. Environ. Sci. Technol. 27, 104-110.

Haigh, S.D., Alcock, R., (1996). A review of the interaction of surfactants with organic contaminants in sewage sludge. Lancaster University, U.K. 185, 161-170.

Hussain, S., Arsad, M., Saleem, M., Kalid, A., (2007). Biodegradation of alpha and beta endosulfan by soil bacteria. 1(25), $120-138$.

Kovacs, M.F., (1965). Thin layer chromatography for pesticide residue analysis. J.Assoc. Agric. Chem., 48, 1018-1022.

Kullmann, S.W., Matsumura, F., (1996). Metabolic pathway utilized Phanerochaete Chrysosporium for degradation of the cyclodine pesticide endosulfan. Appl. Environ. Microbiol. 62, 593-600.

Kumar, K., Devi, S.S., Krishnamurthy, K., Kanade, G.S., Chakrabarti, T., (2007). Enrichment isolation of endosulfan degrading and detoxifying bacteria. Chemosphere, 2, 89-96.

Kumar, M., Philip, L. (2006). Bioremediation of endosulfan contaminated soil and water optimization of operating conditions in laboratory scale reactors. J. Hazard. Mater., 21(2), 354-364.

Kumar, M., Philip, L., (2006). Enrichment and isolation of mixed bacterial culture for complete mineralization of endosulfan. J. Environ. Sci. Health B., 41(1), 81-96.

Kwon, G.S., Kim, J.E., Kim, T.K., Sohn, H.Y., Koh, S.C., Shin, K.S., D.G., (2002). Klebsiella pneumoniae KE-1 degrades endosulfan without formation of the toxic metabolite endosulfan sulfate. FEMS Microbiol. Lett., 215, 255-289.

Martens, R., (1976). Degradation of (8-9 ${ }^{14} \mathrm{C}$ ) endosulfan by soil microorganisms. Appl. Environ. Microbiol., 31, 853-858.

Miller, R.M., Zhang, Y., (1997). Measurement of biosurfactant enhanced solubilization and biodegradation of hydrocarbons. Methods in Biotechnology, Bioremediation protocols, Sheeman human press, Totowa NJ. 2, 59-66.

Sethunathan, N., Megharaj, M., Chen, Z., Singh, N., Kookana, R.S., Naidu, R., (2002). Persistence of endosulfan and endosulfan sulfate in soil as affected by moisture regime and organic matter addition. Bull. Environ. Contam. Toxicol., 68, 725-731.

Shalini, S., Durga, P., Kumar, S., (2000). Biodegradation of alpha and beat isomers of endosulfan and endosulfan sulfate in Indian soils. J. Environ. Sci. Health B., 35(3), 337-46. 
Shivaramaiah, H.M., Kennedy, I.R., (2006). Biodegradation of endosulfan by a soil bacterium. J. Environ. Sci. Health B., 41(6), 895-905.

Singer, M.E., Finnerty, W.R., (1984). Microbial metabolism of straight chain and branched alkanes. In R.M. Atlas (Ed)

Petroleum microbiology, Macmillan pub. New York. 59.

Sutherland, T.D., Weir, K.M., Lacey, M.J., Horne, I., Russel,

R.J., (2002). Gene cloning and molecular characterization of a two enzyme system catalyzing the oxidative detoxification of $\beta$-endosulfan. J. Appl. Microbiol., 92, 541-548.
Trivedy, R.K., Goel, P.K., (1986). Chemical and biological methods for water pollution studies. Environmental Publications. Karad.

Volkering, F., Breure, A.M., Anderi J.G., Rulkens, W.H., Andel, J.G., (1995). Influence of nonionic surfactants on bioavailability and biodegradation of polycyclic aromatic hydrocarbons. Appl. Environ. Microbiol., 61, 1699-1705. Wong, J.W.C., Fang, M., Zhao, Z., Xing, B., (2004). Effect of surfactants on solubilization and degradation of phenanthrene under thermophilic conditions. J. Environ. Qual., 33, 2015-2025.

\section{AUTHOR (S) BIOSKETCHES}

Jayashree, R., Ph.D., Scholar in environmental studies, Anna University, Chennai, India.

Email:p_tamil@yahoo.com

Vasudevan, N., Assistant professor in environmental studies, Anna University, Chennai, India.

Email: annalib@sirnetm.ernet.in

This article should be referenced as follows:

Jayashree, R., Vasudevan, N., (2007). Effect of tween 80 added to the soil on the degradation of endosulfan

by Pseudomonas aeruginosa. Int. J. Environ. Sci. Tech., 4 (2), 203-210 . 